\title{
ROUSSEAU: INDIVÍDUO, REPÚBLICA E EDUCAÇÃO
}

\author{
Antonio Cesar Ferreira da Silva ${ }^{1}$
}

\begin{abstract}
Resumo:
Ao se focalizar o homem, é inevitável tocar na questão de sua formação e da educação, questões que fazem parte da tradição filosófica iniciada por Platão em sua obra A República. Tradição que também é mantida por Rousseau em suas obras. A ênfase que se dá ao assunto gira em torno da adaptação do homem a um determinado contexto, sobretudo ao contexto de uma República, o que pode ser definido a partir de uma pergunta: que processo formativo seria adequado à formação do homem para que ele pudesse se realizar neste contexto? A partir desta pergunta, o presente trabalho buscou discutir a importância da formação como mecanismo para preservar a constituição do indivíduo, a qual possibilite a este a construção de sua própria realização. O caminho metodológico foi percorrido através da análise de duas obras de Rousseau, são elas Emílio ou Da educação e Do contrato social. No Emílio, o filósofo de Genebra aponta para um indivíduo que tem a possibilidade de superar a perspectiva de dependência marcada pela vida em sociedade. Desta forma, se procura apresentar o quão importante é a formação do indivíduo para que ele possa garantir a manutenção e a construção de uma estrutura social, de uma república, que lhe possibilite a sua realização. A estrutura social só poderá se sustentar com a atuação de indivíduos que tenham a si próprios. Isto significa que durante o processo formativo a constituição do indivíduo deve ser assegurada. Só tem a posse de si, quem tem sua constituição mantida por um rigoroso processo formativo. Assim, na medida em que os indivíduos são formados para assumirem uma postura de não dependência, os mesmos terão condições de construírem uma república, cuja dinâmica irá fortalecer a realização de todos os seus membros.
\end{abstract}

Palavras-chave: República. Indivíduo. Educação.

\section{ROUSSEAU: INDIVIDUAL, REPUBLIC AND EDUCATION}

\begin{abstract}
:
When focusing on man, it is inevitable to adress the issue of education, an effort that is part of the philosophical tradition initiated by Plato in his work The Republic. Tradition that is also maintained by Rousseau in his works. The emphasis on the subject is related to the adjustment of man to a particular context, especially the context of a Republic, which can be defined from this question: what formative process would be appropriate for the formation of man so that he could fulfill himself in this context? From this question, the present work aimed to discuss the importance of education as a mechanism to preserve the constitution of the individual, which enables the latter to construct its own realization. The methodological path included the analysis of two works of Rousseau, Emilio and Social Contract. In Emilio, the philosopher of Geneva points to an individual who has the possibility of overcoming the perspective of dependence marked by life in society. In this way, one tries to present how important the formation of the individual is so that he can guarantee the maintenance and the construction of a social structure, of a republic, that enables him to realize it. The social structure can only be sustained by the performance of individuals who have themselves. This means that during the formative process the constitution of the individual must be ensured. It only has the possession of itself, who has its constitution maintained by a rigorous formative process. Thus, to the extent that individuals are formed to assume a nondependency posture, they will be able to build a republic whose dynamics will strengthen the achievement of all its members.
\end{abstract}

Keywords: Republic. Individual. Education.

1 Doutor em Filosofia pela Universidade Federal do Ceará (UFC). Professor Assistente da Universidade Estadual de Feira de Santana. E-mail: acesarfsilva@yahoo.com.br. 
Como a educação pode contribuir para a realização do indivíduo? Platão buscou responder a essa pergunta, pois sabia que sua proposta de república só poderia ser efetivada, na medida em que os homens estivessem preparados para viver e realizar-se no contexto da república. Fora desse contexto, entendia ele, o homem nada poderia ser.

Rousseau segue essa mesma tradição, como se evidencia em sua obra Emílio ou Da educação (1995b) e em alguns capítulos do seu Do contrato social. Em Emílio, o livro IV se destaca por abordar a preparação de um indivíduo para enfrentar a passagem de uma vida de isolamento para uma vida coletiva. Em Do contrato social, o capítulo sétimo do livro II (1987, p. 58), apresenta a figura do legislador, uma espécie de indivíduo que não possui poder algum, mas, ao mesmo tempo, tem uma grande tarefa: a de preparar os indivíduos para a vida em sociedade. É alguém que conhece a natureza humana, mas não é a ela suscetível, uma espécie de referencial que serviria como ponto de apoio para os indivíduos. O ofício do legislador seria o cuidado com a formação, e a atenção aos indivíduos seria a sua principal tarefa. Sem o papel do legislador, uma espécie, portanto, de educador, o indivíduo teria dificuldade de se transformar, a fim de poder usufruir da vida coletiva.

As duas mencionadas obras fornecem, no entendimento do filósofo, os componentes principais para a formação do indivíduo para a vida em sociedade. Que caminhos são apontados nesse processo formativo? Em que se constitui o cerne desse processo? Qual o papel da experiência e do sentimento de existência na formação do indivíduo? Que indivíduo se teria ao fim do processo educacional? Que relação existiria entre a formação do indivíduo e sua realização? Qual seria a relação entre sua realização e sua liberdade?

Tomando-se essas perguntas como roteiro, poder-se-á compreender a centralidade da formação do indivíduo para a constituição da vida republicana proposta por Rousseau e perceber-se o quanto era prioritária para ele essa formação. Sem ela, seria impossível pensar numa república que fosse o lócus fundamental para a realização do próprio indivíduo.

No seu entender, a educação, mais que um instrumento de acúmulo de conhecimentos, seria um processo de preparação do indivíduo para a vida em sociedade, mediante a qual ele se tornaria livre e, em consequência, passível de ser reconhecido. Livre, no sentido de que não seria dependente de outro indivíduo para se realizar, e, vivendo coletivamente, seria reconhecido pelos demais indivíduos como um parceiro fundamental para a construção de uma república justa e igualitária.

\begin{tabular}{|l|l|l|l|l|}
\hline Q Rovista Dialectus & Ano 8 & n. 15 & Agosto-Dezembro 2019 & p. $36-53$ \\
\hline
\end{tabular}




\section{FORMAÇÃO E VIDA REPUBLICANA}

Reconhecendo a importância da vida coletiva, em sua obra Do contrato social, o filósofo genebrino procurou formular um projeto que viabilizasse o aniquilamento da desigualdade entre os homens. Esse projeto viabilizaria uma vida marcada pelo bem comum, projeto avançado proposto simultaneamente em Emílio ou Da educação. Como em toda a tradição filosófica ocidental, um projeto político deve trazer em seu bojo uma proposição formativa. A respeito desse projeto de formação rousseauniano poder-se-iam formular algumas questões. Como deveria ocorrer um processo formativo, a fim de que o indivíduo pudesse vivenciar a experiência de uma sociedade igualitária? Como esse processo poderia formar indivíduos livres para a vida republicana? A vivência em uma sociedade em que não houvesse desigualdade entre os indivíduos e, ao mesmo tempo, esses indivíduos gozassem de sua liberdade é o desafio do processo formativo apresentado pelo filósofo tanto no Emílio, quanto em Do contrato social.

Inicialmente, é necessário que se identifique como, no seu entender, deveria acontecer a formação do indivíduo. Qual o caminho a ser percorrido para a formação de uma criança? E de um jovem? De que maneira deveria ser conduzida sua educação?

Logo no início do livro IV de Emílio, Rousseau destaca a centralidade das paixões para a vida do ser humano, concebendo-as como os componentes centrais de sua existência e de sua sobrevivência. Todo e qualquer tipo de atividade humana seria perpassado pelas paixões, que pautam seus sentidos e suas ações. Tirar do indivíduo suas paixões seria pedir-lhe que deixasse de ser o que ele poderia ser, seria tirar-lhe o potencial de sua existência, seria arrancar-lhe seu querer e sua capacidade de lutar por sua realização:

Nossas paixões são os principais instrumentos de nossa conservação: é, portanto, empresa vã quão ridícula querer destruí-las; é controlar a natureza, é reformar a obra de Deus. Se Deus dissesse ao homem que aniquilasse as paixões que lhe dá, Deus estaria em contradição consigo mesmo. Nunca ele deu tão insensata ordem, nada de semelhante está escrito no coração humano; e o que Deus quer que um homem faça não o faz dizer por outro homem; di-lo ele próprio, escreve-o no fundo do coração do homem. Eu acharia, quem quisesse impedir as paixões de nascerem, quase tão louco quanto quem as quisesse aniquilar. $E$ os que pensassem tal fosse minha intenção até aqui, ter-se-iam certamente muito mal compreendido (ROUSSEAU, 1995, p. 234-235).

\begin{tabular}{|l|l|l|l|l|}
\hline Q Povista Dialectus & Ano 8 & n. 15 & Agosto-Dezembro 2019 & p. $36-53$ \\
\hline
\end{tabular}


Evidencia-se, assim, que a vida do ser humano é e será sempre perpassada pelas paixões, seja no nível do indivíduo, seja no nível das instâncias da vida republicana. Se as paixões são centrais na vida do homem, elas seriam a chave para a formação ideal de todo e qualquer indivíduo, o seu componente estruturante.

Entre as paixões, nosso filósofo ressalta a importância da mais primitiva delas, o amor de si - como já fizera, aliás, no segundo Discurso e em Do contrato social —, ao lado do amor à pátria, que emerge como uma fonte de sustentação importante para a vida da república.

Do mesmo modo que nas duas obras referidas, na passagem que se segue de Emílio, refere-se à importância dos sentimentos, das paixões, na formação do indivíduo, com destaque para o sentimento primeiro, o amor de si:

\footnotetext{
A fonte de nossas paixões, a origem e o princípio de todas as outras, a única que nasce com o homem e não o deixa nunca durante sua vida, é o amor a si mesmo; paixão primitiva, inata, anterior a qualquer outra e da qual todas as outras não são, em certo sentido, senão modificações. [...]. O amor de si mesmo é sempre bom e sempre conforme à ordem. Estando cada qual encarregado de sua própria conservação, o primeiro e o mais importante de seus cuidados é, e deve ser, o de continuamente atentar para ela: e como o faria se não concentrasse nisso seu maior interesse? (ROUSSEAU, 1995, p. 235).
}

O amor de si garante a inteireza do indivíduo, garante sua conservação. Em um processo de socialização, a conservação se revela na formação, que é central para que o indivíduo viva no seio da sociedade. Bem formado, o indivíduo poderá ser um dos artífices, um membro construtor do espaço de vivência coletiva, juntamente com outros membros. $\mathrm{O}$ amor de si emerge no processo formativo como uma paixão central, haja vista que ela norteará as demais. Por meio dela o indivíduo poderá consolidar um espírito de não dependência e o espírito de liberdade colaborativa. O desafio seria, então, encontrar a forma de utilização dessa e das demais paixões, de modo a contribuir para uma formação do indivíduo que pudesse enraizar em seu espírito os signos da liberdade e da cooperação.

Para tanto, é necessário, desde a infância, saber explorar os melhores sentimentos. Enquanto se limita a suas necessidades primeiras, a criança é amável e inocente. No entanto, à medida que cresce, brotam sentimentos de posse e de comparação, começando a se distanciar do sentimento básico da vida, e os desejos em excesso iniciam sua expansão. As crianças começam a buscar e a dominar tudo ao seu redor. Tornam-se autoritárias e querem impor sua vontade aos que delas cuidam.

\begin{tabular}{|l|l|l|l|l|}
\hline Q Rovista Dialectus & Ano 8 & n. 15 & Agosto-Dezembro 2019 & p. $36-53$ \\
\hline
\end{tabular}


Então, a criança torna-se imperiosa, ciumenta, astuciosa, vingativa. Se a dobram à obediência, não vendo a utilidade do que lhe ordenam, atribui-o ao capricho, à intenção de atormentá-la, e se revolta. Se se obedece a ela, vê em qualquer coisa que lhe resista uma rebeldia, uma intenção de contrariá-la; bate a mesa ou a cadeira por lhe terem desobedecido. (ROUSSEAU, 1995, p. 236).

Eis que se evidencia o amor próprio nascente. Como já aqui referido, ao contrário do amor de si, esse sentimento é insaciável e, a cada desejo saciado, abre-se a porta para um novo. Esse sentimento incontrolável leva a criança a não aceitar aquilo que lhe é dito, a não ser que ratifique suas aspirações e pedidos. Esse tipo de conduta leva-a, progressivamente, a se tornar dependente, cada vez mais, de desejos que fogem do alcance dos meios dos adultos, os quais, ainda que quisessem, não poderiam atender a todos, uma vez que ela vai mergulhando no mundo da dependência total dos desejos, tornando-se um ser que pode estar condenando a si próprio. Desde os primórdios de sua existência, seus cuidadores, familiares, etc. procuraram atender suas necessidades básicas. No entanto, com o passar do tempo, a criança descobre que pode conseguir algo mais do que lhe é necessário. Surgem os apetites que em nada tornam sua vida mais completa. Um humor de rebeldia e intolerância toma-lhe conta. A dependência aos desejos em excesso controla seu ser. É quando o amor próprio fala mais alto. Tomada pelo amor próprio, a criança tende, com o passar do tempo, a se tornar tão obsessiva pela vontade de ser atendida, que passa a exigir até mesmo que os outros a amem mais que a si próprios, tornando-se, assim, escrava dos sentimentos dos outros. Esse é um dos componentes das sociedades nas quais não existe igualdade entre os homens, como já o dissera no segundo Discurso. Fruto da vida em grupo, o amor próprio seria algo a ser observado com atenção durante o processo educacional da criança. Como não se pode isolá-la dos males sociais - com o que se poderia evitar o domínio do amor próprio - , convém que se adotem cuidados redobrados em relação à vida em sociedade:

É verdade que não podendo viver sempre sós, dificilmente viverão sempre bons: essa dificuldade mesma aumentará necessariamente com suas relações; e é nisso, principalmente, que os perigos da sociedade nos tornam a arte e os cuidados mais indispensáveis para prevenir, no coração humano, a depravação que nasce de suas novas necessidades (ROUSSEAU, 1995, p. 237).

Rousseau prioriza a necessidade de prevenir-se a corrupção das crianças, o que somente seria possível conhecendo-se profundamente o homem, conhecendo-o, sobretudo, em suas relações. E salienta dois tipos de relações: a relação do homem com as coisas e a relação

\begin{tabular}{|l|l|l|l|l|}
\hline Q Povista Dialectus & Ano 8 & n. 15 & Agosto-Dezembro 2019 & p. $36-53$ \\
\hline
\end{tabular}


dos homens entre si, relações de certa forma já tratadas em obras aqui anteriormente apreciadas.

A relação do homem com as coisas foi objeto de seu segundo Discurso, onde destaca que, graças a essa relação, o ser humano se tornou indivíduo. A relação com as coisas é inevitável, sobretudo pela necessidade que delas tem o homem para atender suas necessidades mais básicas. Quando, pela escassez, a quantidade de coisas já não supriam as necessidades básicas do ser humano, a relação com as coisas serviu de base para outro tipo de relação que o indivíduo estabeleceu: a relação com seus desejos, que o levou a almejar coisas fora de seu alcance, pois tais anseios extrapolavam os meios que possuía para atendê-los.

Como referido anteriormente, exemplifica em Emílio o desejo de uma criança que extrapola todos os limites possíveis, após ter descoberto o mundo e as pessoas que dela cuidam. Poder-se-ia dizer que seria o império das crianças que queriam fazer de seus cuidadores seus escravos. Assim, evidencia-se a abordagem de Rousseau sobre as relações que os indivíduos mantinham com as coisas e com suas paixões. E, mais do que isso, a relação entre os textos de sua obra ao abordar um ponto crucial para a compreensão do desenvolvimento do indivíduo: a análise das dependências que o homem desenvolveu ao abandonar suas paixões naturais. Fica clara a ligação entre a abordagem de duas obras suas. No segundo Discurso, a preocupação do indivíduo que se deteriora com as transformações ocorridas em sua existência, por conta da destruição de sua constituição primeira e, em consequência, a degradação de sua vida e do seu meio. Em Emílio, a indicação de como seria possível uma formação que possibilitasse ao indivíduo realizar-se plenamente. A realização do indivíduo estaria, assim, intrinsecamente relacionada, no contexto social, com um tipo de formação que tanto garantisse a integridade de sua constituição, como o preparasse para a vida comunitária.

Em Emílio, Rousseau indica como as relações com as coisas são desenvolvidas na infância, período em que o ser humano começa a se distinguir de tudo o que o rodeia, sendolhe possível formar uma ideia sobre si próprio. É quando se dá a formulação de sua condição de individualidade, quando começa a estabelecer critérios para suas relações com o mundo. Em um determinando momento, esses critérios serão bem definidos, sobretudo na relação com outros seres humanos. Emerge, assim, a vida moral do indivíduo.

Na relação que se estabelecerá entre os indivíduos, constatar-se-á um processo de desenvolvimento das paixões, e a primeira que eclode dessa relação é oriunda do encontro de

\begin{tabular}{|l|l|l|l|l|}
\hline Q Povista Dialectus & Ano 8 & n. 15 & Agosto-Dezembro 2019 & p. $36-53$ \\
\hline
\end{tabular}


seres que se desejam, daí se originando as demais paixões. O encontro movido pelo sexo seria uma inclinação instintiva natural. No entanto, os componentes sofisticados das relações entre os seres humanos seriam fruto da artificialidade oriunda da instrução e de uma diversidade de componentes da vida em sociedade. As escolhas passariam pelo olhar já permeado pela vida social:

A escolha, as preferências, a afeição pessoal são obra da instrução, dos preconceitos, do hábito; são precisos conhecimentos e tempo para que nos tornemos capazes de amor: só se ama depois de ter julgado, só se prefere depois de ter comparado (ROUSSEAU, 1995, p. 237).

Daí em diante, toda sorte é lançada contra o indivíduo. Os sentimentos novos se distanciam daqueles sentimentos primeiros presentes em sua constituição. Da preocupação consigo próprio, volta-se para a preocupação do olhar dos outros sobre si, preocupação que é fruto de um sentimento de amor de dependência e que o torna escravo dessa situação. É o que diz o filosofo:

Do seio de tantas paixões diversas, vejo a opinião erguer para si mesma um trono inabalável e os estúpidos mortais, escravizados a seu império, não assentarem sua própria existência senão nos julgamentos alheios (ROUSSEAU, 1995, p. 238).

O sentimento que era um componente importante para a integridade do indivíduo ganharia uma forma que agride e destrói essa mesma integridade. Que aqui se entenda integridade como um sinônimo de uma vida boa, na qual o indivíduo gozaria de toda a sua força para viver. Rousseau afirma que as novas paixões são colocadas pelos adultos no coração da criança de forma artificial, portanto, conduzindo-a à dependência. A criança nasce com um espírito de liberdade, daí ser curiosa e aventureira, mas sua corrupção poderia ser evitada, o que já se tornaria impossível no caso dos jovens (Rousseau, 1995, p. 238). Ainda na idade mais tenra é que se devem redobrar os cuidados com o indivíduo, pois é a partir desse tempo que se poderia formar o seu caráter, devendo-se procurar evitar erros na condução de sua formação.

Uma sua observação inicial refere-se às mudanças ocorridas na passagem da infância para a puberdade, mudanças essas geralmente atribuídas às condições naturais que incidem sobre o físico (Rousseau, 1995, p. 238). Essa passagem não seria tão decisiva como parece, argumenta o filósofo, visto que há um outro fator importante, nem sempre observado,

\begin{tabular}{|l|l|l|l|l|}
\hline Revista Dialectus & Ano 8 & n. 15 & Agosto-Dezembro 2019 & p. $36-53$ \\
\hline
\end{tabular}


que é a influência dos outros seres humanos. No contexto social, essa relação é central, pois condiciona os indivíduos a um determinado tipo de conduta, refletindo-se, assim, na forma como esses indivíduos compreenderão a si e aos demais.

Em sua reflexão sobre os componentes que influenciam as mudanças ocorridas na passagem da infância para a adolescência bem como os seus desdobramentos, ele deixa claro que a influência externa na formação das crianças lhes é nociva em dois pontos.

O primeiro é o que se refere à quebra natural e necessária do percurso de formação, quebra que causa anomalias na constituição da criança e as definirá por toda a sua vida. A antecipação de experiências não lhe seria benéfica por ser uma violação à sua própria constituição, pela ausência da maturidade necessária para mergulhar em contextos que lhe são adversos. Sua formação deveria ocorrer de forma natural, para que pudesse amadurecer no tempo certo, amadurecimento natural que revelaria e conservaria a plenitude do próprio indivíduo:

As instruções da natureza são tardias e lentas; as dos homens são quase sempre prematuras. No primeiro caso, os sentidos despertam a imaginação; no segundo, a imaginação desperta os sentidos; ela lhes dá uma atividade precoce que não pode deixar de enervar, de enfraquecer primeiramente os indivíduos e depois a própria espécie, com o andar do tempo. (ROUSSEAU, 1995, p. 239).

Uma segunda consequência da antecipação de etapas da formação ocasionadas pela influência da moral seria a dependência do indivíduo ao que lhe é apresentado pelos outros homens. Ao analisar essa segunda relação, sublinha quão maléfica seria essa influência para a formação do indivíduo no início de sua existência, ressaltando a importância do componente da natureza. Ao se abandonar esse componente e valorizar apenas o aspecto das relações para a sua formação, denuncia os erros e, ao mesmo tempo, os vícios dos indivíduos tomados pela moral social, vícios dos quais deveriam ser protegidos no início de suas vidas. Valorizando-se a própria natureza da criança, seria possível efetivar-se um processo formativo adequado. A valorização da experiência do próprio indivíduo para a sua formação e o seu amadurecimento seriam fundamentais para sua integração ao contexto social e, ao mesmo tempo, sua realização nesse contexto. A antecipação de etapas de amadurecimento poderia violar a formação, pois impediria o desenvolvimento pleno das forças do indivíduo, ferindo-se gravemente sua capacidade de autorrealizar-se.

\begin{tabular}{|l|l|l|l|l|}
\hline Q Povista Dialectus & Ano 8 & n. 15 & Agosto - Dezembro 2019 & p. $36-53$ \\
\hline
\end{tabular}


Segundo o filósofo de Genebra, são os sentidos que impulsionam no indivíduo a capacidade imaginativa, a capacidade criadora. É da própria sensibilidade do indivíduo que emerge sua racionalidade e sua capacidade de resolver seus problemas. Várias são as passagens em seu livro Emílio que demonstram essa sua preocupação, não se constatando uma oposição entre a sensibilidade e a imaginação no processo de formação rousseauniano. À medida que a experiência do indivíduo se consolida, também se aguça sua curiosidade e evolui sua imaginação. A criança aprende pela experiência e, assim, se projeta em uma direção criadora e curiosa. Isso expõe a riqueza de sua constituição que deve ser respeitada para que possa progredir lenta e naturalmente. Apesar de exposto ao contexto social, o homem não perde sua constituição primeira, visto que o amor de si é inato à sua constituição (Rousseau, 1995, p. 235); seguir a sua própria constituição seria o segredo para uma boa formação. Deixar de observar tal orientação seria condená-lo aos mais penosos sacrifícios, sendo o maior deles o de abandonar-se em função dos desejos dos outros indivíduos, o deixar de ser para atender os reclamos de outras vozes. O filósofo aponta o bom caminho:

Segui o espírito da natureza que, colocando nos mesmos lugares os órgãos dos prazeres secretos e os das necessidades repugnantes, inspira-nos os mesmos cuidados em idades diferentes, ora por uma ideia, ora por outra: ao homem pela modéstia, à criança pela limpeza. (ROUSSEAU, 1995, p. 241).

E adverte constantemente, no início do livro IV do Emílio, para o cuidado com a constituição das crianças. O abandono da natureza do indivíduo, de seus sentimentos, no processo formativo, colocaria em perigo seu destino:

Consultai a experiência, compreendereis a que ponto esse método insensato acelera o trabalho da natureza e arruína o temperamento. É uma das causas principais que fazem com que as raças degenerem nas cidades. Os jovens, cedo esgotados, permanecem pequenos, frágeis, mal feitos, envelhecem ao invés de crescer, como a videira que se obriga a dar frutos na primavera, enlanguesce e morre antes do outono (ROUSSEAU, 1995, p. 239-240).

Sua preocupação com a precipitação de etapas educativas é constante, uma vez que poderia violar sua formação, impedindo o desenvolvimento pleno das forças do indivíduo. Por que aguçar precocemente ideias com as quais a criança não pode lidar? Em que isso auxiliaria em sua formação? Um desenvolvimento acelerado da imaginação e, com ela, o da racionalidade não trariam benefício algum:

O menino educado de acordo com sua idade é só. Não conhece apegos senão os do hábito; gosta da irmã como de seu relógio, de seu amigo como de seu cão. Não se

\begin{tabular}{|l|l|l|l|l|}
\hline Qovista Dialectus & Ano 8 & n. 15 & Agosto-Dezembro 2019 & p. $36-53$ \\
\hline
\end{tabular}


sente de sexo nenhum, de nenhuma espécie: o homem e a mulher são-lhe igualmente estranhos; ele não transfere para si nada do que fazem ou dizem: não o vê nem o entende, ou não presta atenção; os discursos deles não o interessam, como não lhe interessam os exemplos: nada disso é feito para ele. (ROUSSEAU, 1995, p. 243244).

O desenvolvimento precipitado se dá no cotidiano pelo comportamento dos adultos, pela bajulação que recebe a criança no dia a dia, por exemplo. O ideal seria que a criança ficasse distante do universo dos adultos, do jogo de sutilezas e aparências do mundo social, evitando-se, assim, esses vícios. Quanto mais tempo esse contato pudesse ser retardado, tanto melhor.

Ao contrário da aceleração da vida da sociedade, a vida da natureza segue um percurso cadenciado e, assim, de forma gradual, a maturidade deve se processar. Não há uma negação do mundo civilizado, mas uma preocupação com o indivíduo para que ele não absorva esses males.

Por meio da experiência, guiada pelo curso natural da vida, a criança chegaria ao universo dos adultos com condição de rejeitar aquilo que lhe seria maléfico ou não, conduzindo-se por suas próprias pernas pelo universo da sociabilidade. Nunca se deveria expulsar da criança sua naturalidade. Não se pode fazer dela o que ela ainda não é. Os mimos e as bajulações geralmente são uma verdadeira armadilha, fazendo-a pensar que tem mais idade do que a que verdadeiramente possui. Envelheceria antes mesmo de atingir a maturidade física.

Em vez de se fomentar no coração da criança anseios inalcançáveis que tendem a esgotá-la, deve-se estimular uma vida natural, recomenda Rousseau, deixando que ela possa experimentar o mundo a partir de seu próprio olhar.

E, quando da passagem da infância para a puberdade, que se estimule não o amor próprio, mas o sentimento da amizade, sentimento que permite que se incentive o jovem a se dar conta dos outros indivíduos. Se a criança deveria ser formada o mais longe possível do convívio com o mundo social, chegada, porém, a juventude, momento chave na formação do indivíduo, é necessário que seja preparado para o convívio social, e a expectativa da amizade seria o melhor sentimento para isso, sentimento benéfico na medida em que despertaria nele o que Rousseau chama de sementes da humanidade. Veja-se o quanto ele deposita na boa condução do jovem a possibilidade de se ter, por meio da amizade, a construção de boas relações entre os indivíduos:

\begin{tabular}{|c|c|c|c|c|}
\hline Qevista Dialectus & Ano 8 & n. 15 & Agosto - Dezembro 2019 & p. $36-53$ \\
\hline
\end{tabular}


Sempre verifiquei que os jovens corrompidos cedo, e entregues às mulheres e ao deboche, eram inumanos e cruéis; a fuga do temperamento tornava-os impacientes, vingativos, furiosos; sua imaginação, tomada por um só objeto, recusa-se ao resto; não conheciam nem piedade nem misericórdia; teriam sacrificado pai, mãe e o universo inteiro ao menor de seus prazeres. Ao contrário, um jovem educado dentro de uma simplicidade feliz é levado pelos primeiros movimentos da natureza às paixões ternas e afetuosas.

Seu coração complacente comove-se com as atribulações de seus semelhantes; ele freme de alegria quando revê sua camarada, seus braços sabem encontrar amplexos carinhosos, seus olhos sabem verter lágrimas de ternura; ele é sensível à vergonha de desagradar, ao remorso de ter ofendido. (ROUSSEAU, 1995, p. 246).

O princípio da amizade faria fermentar no jovem o espírito da solidariedade, que se assemelha ao sentimento da piedade, aqui já abordado, anterior à vida do homem em sociedade, pelo qual não suportava o sofrimento de um outro ser vivo. Esse sentimento lhe permitiria envolver-se com os demais de forma saudável, estabelecendo relações que não se assentariam na dependência. $\mathrm{O}$ desenvolvimento do sentimento da amizade seria a chave para que se estabelecesse o distanciamento dos vícios da sociedade e lhe criasse a possibilidade de se tornar responsável pela transformação da sociedade viciada.

Entretanto, não basta apenas o sentimento da amizade. Que não se dê conhecimento ao jovem das estruturas da sociedade, que se evite que conheça a sociedade do luxo e da corrupção dos costumes, antes de aprofundar seu conhecimento sobre os seres que construíram essa mesma sociedade, se não se quiser correr o risco de corrompê-lo:

\begin{abstract}
Se quereis pois suscitar e alimentar no coração de um jovem os primeiros movimentos da sensibilidade nascente, e voltar seu caráter para a piedade e a bondade, não façais germinar nele o orgulho, a vaidade, a inveja, pela enganosa imagem da felicidade dos homens; não mostreis primeiramente a seus olhos a pompa das cortes, o fausto dos palácios, a sedução dos espetáculos; não o passeis pelos círculos, em brilhantes assembleias, não lhes mostreis o exterior da grande sociedade, senão depois de tê-lo posto em condições de apreciá-la em si mesma. Mostrar-lhe o mundo antes que conheça os homens, não é formá-lo, é corrompê-lo; não é instruí-lo, é enganá-lo. (ROUSSEAU, 1995, p. 247).
\end{abstract}

É preciso conhecer bem o homem, adverte Rousseau, e essa é uma tarefa do seu esforço intelectual, pois o segredo dos problemas do homem se encontram no próprio homem, assim como as soluções. Isso fica evidenciado nas três obras que vimos aqui analisando. A partir da constituição dos sentimentos humanos pode-se formular um processo formativo que conduza o jovem, preparando-o para enfrentar todas as vicissitudes da vida em sociedade. Isso não se realizaria como um processo racional, mas, sobretudo, como um processo sentimental. Não basta apenas tomar conhecimento, é preciso estar preparado, do ponto de vista do sentir,

\begin{tabular}{|l|l|l|l|l|}
\hline Q Povista Dialectus & Ano 8 & n. 15 & Agosto-Dezembro 2019 & p. $36-53$ \\
\hline
\end{tabular}


para que se possa experimentar uma determinada realidade. As observações de Rousseau a esse respeito se repetem inúmeras vezes. Em diversas passagens de Emílio, a importância atribuída aos sentimentos evidencia sua centralidade para o processo formativo. Se, por um lado, tem-se uma estrutura que ameaça o jovem indivíduo - a sociedade —, por outro, é necessário encontrar-se o caminho para a superação de seus males. Garantido o distanciamento desses males, ter-se-ia um jovem indivíduo bem formado, bem-educado:

\begin{abstract}
Mas não vos apresseis em julgar os jovens com esta regra, sobretudo os que, tendo sido educados como o devem ser, não têm nenhuma ideia das penas morais que nunca experimentaram, pois, mais uma vez, só podem ter pena dos males que conhecem e esta aparente insensibilidade, que só vem da ignorância, transforma-se dentro em breve em ternura, quando começam a sentir que há na vida humana mil dores que desconhecem. Quanto a meu Emílio, se revê simplicidade e bom senso em sua infância, estou certo de que terá alma e sensibilidade em sua juventude, porque a verdade dos sentimentos está muito ligada à justeza das ideias. (ROUSSEAU, 1995, p. 254-255).
\end{abstract}

Dessa forma, o jovem estaria longe de se tornar contaminado pela sociedade, envolvido com as aparências do mundo das vaidades e dos vícios, uma vez que nada do que experimentasse pertenceria ao seu mundo. O poder aparente embriagaria e turvaria os seus sentimentos:

\begin{abstract}
Tomemos dois jovens saindo da primeira fase da educação e entrando na sociedade por duas portas diretamente opostas. Um sobe subitamente ao Olimpo e frequenta a mais brilhante sociedade; levam-no à Corte, às casas dos grandes e dos ricos, e das mulheres bonitas. Imagino-o festejado por toda parte e não examino o efeito dessa acolhida sobre seu espírito: suponho que resiste. Os prazeres voam à sua frente, novos objetos o divertem; a tudo ele se entrega com um interesse que seduz. Vós o vedes atento, solícito, curioso; sua primeira admiração vos impressiona; vós o considerais satisfeito; mas olhai para sua alma. Vós imaginais que ele está contente; eu creio que ele sofre.

Primeiramente, que percebe ele ao abrir os olhos? Uma multidão de pretensos bens que não conhecia, mas que, estando em sua maioria apenas um momento a seu alcance, não parecem mostrar-se a ele senão para que lamente estar privado deles. Se passeia num palácio, logo vedes, por sua curiosidade inquieta, que se pergunta porque a casa paterna não é igual. Todas as suas perguntas vos dizem que ele se compara sem cessar ao dono dessa casa e tudo o que encontra de mortificante nesse paralelo aguça sua vaidade, revoltando-a. (ROUSSEAU, 1995, p. 255).
\end{abstract}

Vivendo em função da opinião dos demais, o indivíduo civilizado, para obter as benesses da sociedade, precisa valer-se de máscaras para sobreviver:

O homem da sociedade está todo inteiro na sua máscara. Não estando quase nunca em si mesmo, quando está se acha estranho

\begin{tabular}{|l|l|l|l|l|}
\hline Q Rovista Dialectus & Ano 8 & n. 15 & Agosto-Dezembro 2019 & p. $36-53$ \\
\hline
\end{tabular}


e mal à vontade. $\mathrm{O}$ que é, não é nada, o que parece, é tudo para ele. (ROUSSEAU, 1995, p. 258).

Abandonar o indivíduo nas estruturas dos estados de sua época, diz o filósofo, seria condená-lo à dependência e à escravidão, e recomenda a preservação da singularidade do indivíduo nos seus primeiros anos de vida, bem como uma orientação adequada ao jovem para garantir-lhe o seu potencial de existência, a sua capacidade e a sua autossuficiência.

Uma sua importante recomendação se refere às comparações, já comentadas anteriormente, que iniciam o indivíduo nos primeiros passos e lhe retiram sua condição de autossuficiência, processo que pode se iniciar já na infância. Após descobrir que é o centro das atenções, a criança inicia as comparações entre tudo aquilo que a circunda, e pode escolher aquilo que lhe interessa, movendo-se por desejos que não podem ser realizados. Ao jovem, já envolto pelos sentimentos mais funestos, as comparações trazem as informações sobre o verdadeiro lugar que ocupa na vida social e percebe que sempre lhe falta alguma coisa, processo que tende a enfraquecê-lo cada vez mais. Não tendo sido devidamente preparado para ter contato com o luxo do mundo social, já se encontra num labirinto que o aprisiona e o faz escravo de um contexto que o sufoca todos os dias, sem mecanismos para escapar. Incapaz de se auto conduzir, tem comprometida, desse modo, sua possibilidade de realização. Eis no que pode redundar o descuido na formação da criança e do jovem:

\footnotetext{
Primeiramente, que percebe ele ao abrir os olhos? Uma multidão de pretensos bens que não conhecia, mas que, estando em sua maioria apenas um momento a seu alcance, não parecem mostrar-se a ele senão para que lamente estar privado deles. Se passeia num palácio, logo vedes, por sua curiosidade inquieta, que se pergunta porque a casa paterna não é igual. Todas as suas perguntas vos dizem que ele se compara sem cessar ao dono dessa casa e tudo o que encontra de mortificante nesse paralelo aguça sua vaidade, revoltando-a. Se depara com um jovem mais elegante do que ele, vejo-o murmurar em segredo contra a avareza de seus pais. Está mais bem vestido do que outro, tem a dor de ver esse outro dominá-lo por seu nascimento ou seu espírito, e todo o seu luxo humilhado por um simples terno de pano ordinário. (ROUSSEAU,1995, p. 255).
}

Para evitar-se a dependência e a corrupção do indivíduo, insiste Rousseau na necessidade de, desde o início, submeter o indivíduo a um lento processo de formação que respeite a sua singularidade e, ao mesmo tempo, de retardar o máximo possível seu contato com os costumes da sociedade, como um último esforço para introduzir o jovem na vida social da melhor maneira possível.

\begin{tabular}{|l|l|l|l|l|}
\hline Q Povista Dialectus & Ano 8 & n. 15 & Agosto-Dezembro 2019 & p. $36-53$ \\
\hline
\end{tabular}


Se, inicialmente, apresenta-se ao jovem o homem em suas contradições da espécie, faz-se necessário mostrar-lhe o homem da vida social. Até esse momento, o jovem se detivera apenas sobre si mesmo. Seria necessário, então, mostrar-lhe os demais indivíduos. Ao conhecê-los, o jovem iniciaria um processo de comparações que o levaria à busca de se sobressair perante os demais. É nesse momento que todos os cuidados devem ser tomados, pois o jovem se encontrará diante do envolvimento com o amor próprio que lhe trará todos os tipos de sentimento. É, então, que a busca pelo lugar que deverá ocupar na sociedade se intensificará, definindo-se os sentimentos que prevalecerão. Diante de escolhas que deverá fazer, decidirá por reproduzir o que encontrará na sociedade, ou optará pela manutenção de sentimentos que valorizem a benevolência e a comiseração. $\mathrm{O}$ caminho que o jovem indivíduo deverá percorrer após o primeiro contato com os demais homens requer uma orientação, orientação que deve partir do conhecimento dos homens enquanto seres de sociedade, evidenciando-se o contexto das desigualdades que foram estabelecidas entre os homens.

Para Rousseau, só se pode conhecer a sociedade pelos homens, e os homens, pela sociedade. Conhecendo-se os homens em suas relações, tem-se a verdadeira imagem da realidade. Ao se aprofundar no estudo das relações humanas, o jovem indivíduo teria a possibilidade de enxergar a vida como ela é de fato, sem as máscaras elaboradas pela sociedade decorrentes do amor próprio.

O indivíduo jovem, o seu Emílio, deve entender a relação que ocorre entre o estudo do homem e o estudo da sociedade. Tratar esses estudos de forma separada faria com que não apreendesse nenhum dos dois:

É preciso estudar a sociedade pelos homens, e os homens
pela sociedade: os que quiserem tratar separadamente da
política e da moral nunca entenderão nada de nenhuma
das duas. (ROUSSEAU, 1995, p. 266).

O estudo do homem lhe indicaria que, enquanto manteve sentimentos moderados e simples em seu coração, pôde preservar sua independência e sua liberdade (p. 266) e a simplicidade assegurou-lhe uma vida de igualdade. O jovem deve ser introduzido no conhecimento do homem e da sociedade a partir do conhecimento do coração do homem, de seus sentimentos. É com a decifração dos sentimentos da constituição dos indivíduos que Rousseau pôde compreender a história da humanidade, bem como o desenvolvimento das

\begin{tabular}{|l|l|l|l|l|}
\hline Q Revista Dialectus & Ano 8 & n. 15 & Agosto-Dezembro 2019 & p. $36-53$ \\
\hline
\end{tabular}


desigualdades e dos problemas humanos. "Eis, agora o estudo que nos interessa; mas para realizá-lo cumpre começar por conhecer o coração humano", manifesta ele (Rousseau, 1995, p. 266).

Conhecer o homem a partir dessa perspectiva seria ultrapassar as máscaras oriundas da vida social que encobrem o que de fato é o homem da sociedade. A verdadeira face do homem social, civilizado, já fora apontada pelo filósofo em outras obras suas - o Discurso sobre a origem e os fundamentos da desigualdade entre os homens e o Discurso sobre as ciências e as artes. Em Emílio, apresenta a necessidade do conhecimento da verdadeira face do homem como uma das etapas do processo educacional do jovem, para que possa avaliar bem o mundo no qual ele terá que de viver, e fazer sua melhor opção de vida. Se, durante toda a infância e adolescência, aprendeu apenas a partir de sua própria experiência — uma aprendizagem a cada situação —, o que lhe permitiu perceber a si próprio e o mundo que o rodeava, na fase juvenil, deverá conhecer o mundo a partir da experiência dos demais indivíduos, sendo o estudo das relações entre os homens o principal conteúdo da formação do jovem. Esse estudo o ajudará a compreender que a origem do mal não se encontra na natureza do homem, mas no processo histórico que o levou a construir um mundo que é contrário à sua própria natureza. Esse momento da aprendizagem deve ser pensado de forma meticulosa. A questão não envolve a mera apreensão dos dados da realidade, mas requer um elemento mais importante que é o da formação moral. Esse componente não pode se constituir pelo simples acúmulo de informações, uma vez que a opção de vida deve ser construída, pois o puro conhecimento não garante uma formação adequada. Desvendar as raízes dos males que afligem os homens requer sentimentos adequados, os quais, bem conduzidos por uma boa formação, desenvolverão no jovem uma boa conduta moral. A opção por um tipo de conduta, além de passar pelo crivo da escolha, pelo crivo da racionalidade, passa pelo cultivo dos melhores sentimentos. A escolha de conduta é racional, se efetiva a partir de um longo processo de cultivo dos sentimentos. O cultivo do sentimento de amizade por parte do indivíduo jovem aproxima os homens para uma vida em grupo, em que a cooperação é a lógica da vivência. Daí ser fundamental que se tome todo o cuidado possível quando, durante seu processo educacional, o jovem for iniciar o estudo dos homens em sociedade. Sua primeira recomendação é a de que a vida social seja estudada a partir dos livros de História. E quais seriam os motivos para isso?

\begin{tabular}{|l|l|l|l|l|}
\hline Q Povista Dialectus & Ano 8 & n. 15 & Agosto-Dezembro 2019 & p. $36-53$ \\
\hline
\end{tabular}


O primeiro motivo apontado é a temeridade de, ainda muito jovem e inexperiente, o indivíduo achar naturais as perversões e injustiças produzidas pela sociedade, dando-lhe a impressão de que esse contexto seria oriundo da própria natureza humana, e podendo provocar uma distorção em seu espírito, fazendo-o acomodar-se a essas mazelas e acreditar que o contexto revelaria a verdadeira dinâmica das coisas. Um espírito ainda muito jovem não estaria plenamente preparado para se defrontar com estruturas viciadas, seria uma temeridade. De tanto condicionar o olhar a uma determinada realidade, acaba-se acreditando nela, e o hábito se transformaria em referência:

Habituar-se-á ao menos ao espetáculo do vício, a ver os maus sem horror, como a gente se acostuma a ver os desgraçados sem piedade. Dentro em breve a perversão generalizada lhe servirá menos de lição que de desculpa; dirse-á que, se o homem é assim, ele não deve querer ser de outro jeito. (ROUSSEAU, 1995, p. 267).

O segundo motivo apresentado é relativo ao outro extremo do estudo inicial da vida social. Se o primeiro indica que se deve evitar um estudo em contato direto com a sociedade, o segundo é o de que se evite um estudo da sociedade extremamente distante da realidade social. Nem um mergulho direto, nem uma distância extrema. Como o primeiro, esse segundo motivo também poderia produzir anomalias na formação do jovem indivíduo, se lhe fossem fornecidas informações genéricas sobre a vida em sociedade, sem que se indicassem as verdadeiras informações sobre a vida dos homens, os componentes históricos e suas contradições. Seria um estudo superficial que se situaria no campo de uma metafísica estéril, metafísica que explica a sociedade por meio de elementos que lhe são estranhos, de fatores externos que apontariam as raízes da dinâmica social, ou seja, apenas um artefato da retórica metafísica que não explica as verdadeiras causas da origem da sociedade e dos seus males. Essa perspectiva que se constitui pelo olhar de outra pessoa, sendo apresentada ao jovem como verdade, geraria uma dependência em relação à opinião de outrem, impossibilitando-o de construir, com o seu próprio observar, suas conclusões sobre o mundo social. É exatamente o oposto a isso que Rousseau aponta como importante no processo educacional, por entender que o jovem deverá construir seu arcabouço de conhecimento a partir de suas próprias experiências, o que lhe concederia a autonomia suficiente para se tornar um indivíduo capaz de se autoconstruir.

\begin{tabular}{|l|l|l|l|l|}
\hline Q Povista Dialectus & Ano 8 & n. 15 & Agosto-Dezembro 2019 & p. $36-53$ \\
\hline
\end{tabular}


Os dois motivos estão em polos extremos. Enquanto um mergulha o indivíduo diretamente na vida social, o outro permite-lhe um distanciamento dela. Tem-se, por parte do filósofo, a tentativa de promover ao jovem indivíduo um contato com a realidade, ao mesmo tempo em que o preserva dos males oriundos dessa mesma realidade, procedimento que lhe permitiria manter o bom desenvolvimento dos seus sentimentos, que já viria cultivando desde a sua infância, e, ao mesmo tempo, capacitá-lo para um julgamento da realidade social. Temse uma dinâmica de formação que tem os componentes dos sentimentos do indivíduo e, ao mesmo tempo, a capacidade de reflexão sobre o que passa a conhecer da realidade. De posse de uma avaliação, o jovem realizaria sua opção de inserção na sociedade, uma inserção que poderia ser a de aceitação do contexto encontrado ou a sua rejeição. Alcançar-se-ia, dessa forma, uma unidade no processo de formação do indivíduo, entre aquilo que ele desenvolve em seu sentimento de existência e as reflexões sobre a realidade investigada.

Vê-se, por conseguinte, que o filósofo transita entre uma formação que valoriza a experiência e os sentimentos e aquela que reconhece a importância da atividade reflexiva. Ambas são componentes da própria constituição do indivíduo desde os tempos mais remotos, como se pode constatar nas reflexões que desenvolve em suas obras, e que tem como ponto de partida a sua antropologia delineada no segundo Discurso. Além disso, o próprio Do contrato social é a tentativa de se preservar, na esfera política, a constituição do indivíduo focalizada pela antropologia rousseauniana. O cuidado com o desenvolvimento dos sentimentos seria fundamental para uma formação que alimentasse no jovem: a rejeição a todo e qualquer tipo de vício social; a adesão a uma vida de solidariedade; o desenvolvimento do espírito de liberdade.

É imperioso frisar que Rousseau não exclui do processo educacional momentos distintos da formação: o aspecto sensitivo e o aspecto intelectivo. Reconhece uma interação entre essas duas faces, que devem se desenvolver simultaneamente. Ao mantê-las, reconhece a unidade do indivíduo, sua constituição que não pode ser fraturada. Sua preocupação não é com uma formação que apenas mantivesse a pureza do indivíduo, que o conservasse para sempre em um estágio de infantilidade, nem que o inserisse numa esfera de mera formação intelectual. A formação que se mantiver atenta às duas faces do indivíduo - a face dos sentimentos e a face da reflexão — permitirá que o indivíduo se preserve dos males sociais.

No entanto, é a partir da adolescência e da juventude que se evidencia a necessidade da utilização da face mais reflexiva da formação, quando o jovem indivíduo deve

\begin{tabular}{|l|l|l|l|l|}
\hline Q Povista Dialectus & Ano 8 & n. 15 & Agosto-Dezembro 2019 & p. $36-53$ \\
\hline
\end{tabular}


conhecer o mundo dos homens, a sociedade. E esse conhecimento se dará a partir das experiências vividas pelos outros indivíduos. É nessa fase de sua existência que deverá estudar a história dos homens e, a partir desse estudo, poderá conhecer os detalhes da sociedade, as raízes dos males sociais. Aliando o que desenvolveu em seus sentimentos à sua análise da história, será capaz de realizar o julgamento da sociedade, permitindo-lhe escolher como desejará viver no seio da sociedade. A escolha, que passa pelo crivo da racionalidade, tem, entretanto, como suporte os sentimentos e os valores acumulados ao longo de sua formação, assim como seu sentimento de amizade, que já se teria desenvolvido. Sua participação saudável na vida social seria, assim, fruto do processo formativo que teria desenvolvido plenamente. E esse desenvolvimento pleno passa, sobretudo, pelo sentimento de existência.

\section{REFERÊNCIAS :}

ROUSSEAU, Jean-Jacques. Oeuvres complètes. Édition publiée sous la direction de Bernard Gagnebin et Marcel Raymond. Paris: Gallimard, 1959. 5v. (Bibliothèque de la Pléiade).

ROUSSEAU, Jean-Jacques. Émile ou De l'éducation. Chronologie et introduction par Michel Launay. Paris: Flammarion, 1966.

ROUSSEAU, Jean-Jacques. Do Contrato social. Tradução de Lourdes Santos Machado. 4. ed. São Paulo: Nova Cultural, 1987. (Os Pensadores).

ROUSSEAU, Jean-Jacques. Discurso sobre a origem e os fundamentos da desigualdade entre os homens. Tradução de Lourdes Santos Machado. 4. ed. São Paulo: Nova Cultural, 1987-1988a. (Os Pensadores).

ROUSSEAU, Jean-Jacques. Discurso sobre as ciências e as artes. Tradução de Lourdes Santos Machado. 4. ed. São Paulo: Nova Cultural, 1987-1988b. (Os Pensadores).

ROUSSEAU, Jean-Jacques. Discurso sobre a economia política e Do Contrato social. Tradução de Maria Constança Peres Pissarra. Prefácio de Bento Prado Júnior. Petropólis, RJ: Vozes, 1995a.

ROUSSEAU, Jean-Jacques. Emílio ou Da educação. Tradução de Sérgio Milliet. 3. ed. Rio de Janeiro: Bertrand Brasil, 1995.

\begin{tabular}{|l|l|l|l|l|}
\hline Q Rovista Dialectus & Ano 8 & n. 15 & Agosto-Dezembro 2019 & p. $36-53$ \\
\hline
\end{tabular}

